Original Research Article

\title{
Evaluation of adverse drug reactions of first line antiretroviral drugs in a tertiary care centre of Telangana, India
}

\author{
Padmaja Gabbita, Margaret V. Jillapegu*, Saikiran L. N. Vangala, Jahnavi Tiruveedhula
}

\author{
Department of Pharmacology, \\ Pharmacology, Gandhi Medical \\ College, Secunderabad, \\ Telangana, India
}

Received: 24 September 2018 Accepted: 02 October 2018

\section{*Correspondence to: \\ Dr. Margaret V. Jillapegu, Email: margaretviola67@ yahoo.com}

Copyright: (C) the author(s), publisher and licensee Medip Academy. This is an openaccess article distributed under the terms of the Creative Commons Attribution NonCommercial License, which permits unrestricted noncommercial use, distribution, and reproduction in any medium, provided the original work is properly cited.

\begin{abstract}
Background: The introduction of highly active anti-retroviral therapy (HAART) has led to a significant reduction in AIDS related morbidity and mortality. Most of the adverse drug reactions are preventable. So continuous evaluation will benefit Antiretroviral treatment that helped to achieve ultimate goal of making treatment safer and more effective to patients. The present study was designed to monitor and analyse the incidence, type and nature of adverse events to first line Antiretroviral drugs.

Methods: A cross sectional observational study was conducted at Antiretroviral treatment center of Gandhi Hospital, Secunderabd, Telangana. The study was conducted over a period of 6 months involving all HIV patients. After initiation of $1^{\text {st }}$ line regimen- tenofovir $300 \mathrm{mg}+$ lamivudine $300 \mathrm{mg}+$ efavirenz $600 \mathrm{mg}$ (TLE), patients were followed for any adverse event. Descriptive statistics was used for analysis of data.

Results: Out of 453 studied, 47 patients developed adverse events. A total of 79 adverse events were reported. The assessment of total adverse drug reaction profile revealed cutaneous $44.30 \%$, hematological $40.50 \%$, renal $11.39 \%$, gastrointestinal $3.79 \%$. WHO-UMC causality assessment scale showed $76.5 \%$ and $23.4 \%$ Adverse events as probable and possible respectively. Hartwig and Siegel severity scale revealed $93.6 \%, 2.1 \%$ and $4.3 \%$ as mild, moderate and severe cases respectively.

Conclusions: The TLE regimen found with lower adverse events in this study. The study focuses the importance of active adverse event monitoring to detect early toxicities and to support safe use of anti-retroviral treatment.
\end{abstract}

Keywords: Antiretroviral treatment, Adverse drug reactions, HIV, Hartwig siegel scale, WHO-UMC causality scale

\section{INTRODUCTION}

Anti-retroviral toxicity is an increasingly important issue in the management of HIV infected patients. ${ }^{1}$ The introduction of highly active anti-retroviral therapy (HAART) has led to a significant reduction in AIDS related morbidity and mortality, which has changed the outlook of HIV infection from being a rapidly fatal to chronically manageable infection. ${ }^{2}$ Antiretroviral drugs mainly suppress viral load and thus restoring the immune function. ${ }^{3}$ In India, NACO has made efforts to make generic HAART available which is very economical due to which many HIV infected individuals are receiving the therapy. ${ }^{4}$ Many studies in the developing countries have demonstrated the safety tolerability and efficacy of generic HAART. ${ }^{5}$ Despite these gains, adverse reactions to these medicines remain a significant public health concern and may compromise the effectiveness of the Antiretroviral treatment (ART) program. ${ }^{6}$ Adverse drug reactions (ADRs) have been one of the most important limiting factors to the success of HAART because they are responsible for new co-morbidities noticeable by the patient or their families and may result in decreased adherence to the treatment which consequently might lead to the virological failure and poor prognosis. ${ }^{7}$ The advent of new generation drugs with relatively low toxicity into the antiretroviral armamentarium is some hope that 
deleterious effects of HAART related ADRs in HIV patients would decrease. ${ }^{7,8}$

Most of the ADRs are preventable. The incidence of ADRs among patients on antiretrovirals from both developing and developed countries is ranging between $11 \%$ and $35.9 \%$ with incidence being as high as $54 \%$ co-existent with opportunistic infections. ${ }^{3}$ So continuous evaluation will benefit the ART that helped to achieve ultimate goal of making treatment more safe and effective to the patients and early modification of drug regimen to improve patient compliance and tolerability to the therapy.

The present study was thus designed to monitor and analyse the incidence, type and nature of adverse events to first line antiretroviral drugs in a tertiary care ART center of Gandhi hospital.

\section{METHODS}

A crossectional observation study was conducted at ART center of a tertiary care hospital - Gandhi Hospital, Secunderabad, Telangana, India. The study was conducted over a period of 6 months from March 2018 to August 2018 involving all the HIV subjects registered within this time period. Due permission was obtained from the nodal officer of the center. The study was undertaken after obtaining approval from the institutional ethics committee and written informed consent was obtained from all subjects before their inclusion in the study.

The study population consisted of HIV positive subjects of either gender aged 20 to 60 years of age were initiated on $1^{\text {st }}$ line HAART regimen: tenofovir $300 \mathrm{mg}+$ lamivudine $300 \mathrm{mg}+$ efavirenz $600 \mathrm{mg}$ (TLE) that strictly followed the guide lines of NACO by the medical officers In-charge at ART centre Gandhi hospital. Patients who are not on cotrimoxazole prophylaxis or on co-trimoxazole prophylaxis after 2 weeks are included in the study. ${ }^{9}$ Patients receiving $2^{\text {nd }}$ and $3^{\text {rd }}$ line ART and those on concomitant treatment for antituberculosis therapy and patients with any other comorbidities like diabetes mellitus, hypertension, chronic kidney disease, pregnant women, lactating mothers and Immune reconstitution inflammatory syndrome (IRIS) patients were excluded from the study.

After initiation of the therapy the patients were followed up for three months for any adverse events. At each follow up visit, scheduled or unscheduled, adverse clinical events, its type, severity, demographic details, relevant history and abnormal laboratory findings are noted. The case sheets of the included subjects were studied, and the information obtained was entered into the suspected adverse event (AE) reporting form, as adopted in the Pharmacovigilance Programme of India (PVPI). All the information collected, and identity of the subjects is kept confidential.

Any AE observed by the treating physician was noted in the ADR form and any untoward event was labeled as an $\mathrm{AE}$ only after the concurrence of treating physician.
Whenever any other information was required, the treating physician was contacted. Investigations for confirmation of adverse events were carried out with the consent of concerned physician. In this study only, Adverse events were monitored. No observations were made in the diagnosis or management of the subjects.

Details of AE collected included type, severity, seriousness, outcome, treatment given, and causality assessment was made as per WHO -UMC causality assessment scale. ${ }^{10}$ The severity of each reported ADR was assessed using Hartwig and Siegel scale. ${ }^{11}$ Descriptive statistics such as percentages of the obtained data was performed.

\section{RESULTS}

A total of 453 patients were treated by the 1 st line antiretroviral TLE regimen of which 211 are male patients, 241 female patients and 1 transgender patient. Out of 453 patients studied 47 patients developed AEs of which 14 $(29.7 \%)$ were males and 33(70.2\%) were females (Figure 1). A total of 79 adverse events were reported.

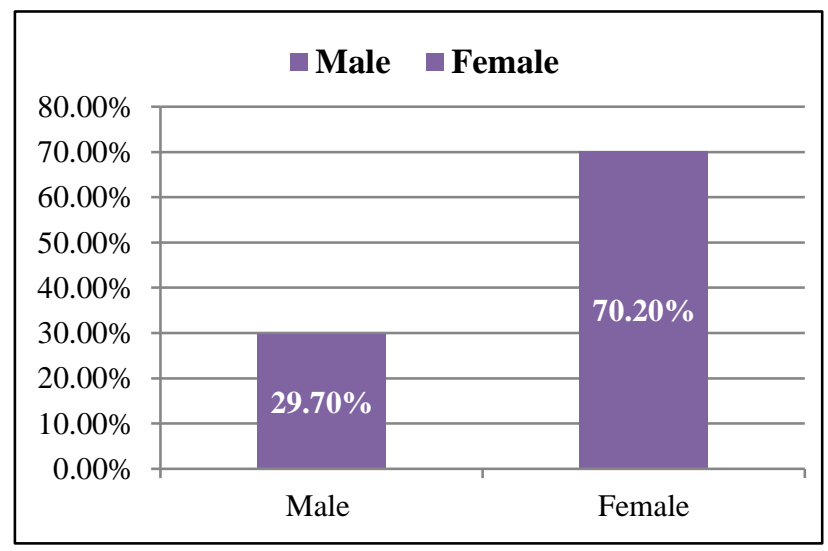

Figure: 1 Comparison of adverse events to TLE regimen among males and females.

Table 1: Patients with adverse drug reactions in different age groups.

\begin{tabular}{|lll|}
\hline $\begin{array}{l}\text { Age } \\
\text { group }\end{array}$ & $\begin{array}{l}\text { Total patients } \\
\text { presenting with ADR's }\end{array}$ & Frequency \% \\
\hline$<18$ & 4 & 8.51 \\
\hline $18-30$ & 7 & 14.89 \\
\hline $31-40$ & 19 & 40.42 \\
\hline $41-50$ & 12 & 25.53 \\
\hline $51-60$ & 5 & 10.63 \\
\hline
\end{tabular}

Age group analysis revealed that patients within the age group of 31-40 years presented with maximum ADRs n= $19(40.42 \%)$ followed by $41-50$ years $n=12(25.53 \%)$ (Table 1).

The cutaneous ADRs presented as generalised rash $\mathrm{n}=30$ (37.9\%), pruritis, maculopapular rash and erythema. The 
hematological ADRs were anemia $n=31(39.2 \%)$ and pancytopenia $\mathrm{n}=1(1.26 \%)$. The renal toxicity presented as renal failure $n=6(7.59 \%)$, acute kidney injury $n=2(2.53 \%)$ and Nephrotoxicity $\mathrm{n}=1(1.26 \%)$ (Table 2$)$.

Table 2: Frequency of various adverse drug reactions.

\begin{tabular}{|ll|}
\hline ADR description & Frequency (\%) \\
\hline Diarrhea & $1(1.26 \%)$ \\
\hline Dysphagia & $1(1.26 \%)$ \\
\hline Gastritis & $1(1.26 \%)$ \\
\hline Generalized rash & $30(37.9 \%)$ \\
\hline Pruritis & $3(3.79 \%)$ \\
\hline Maculo papular rash & $1(1.26 \%)$ \\
\hline Erythema & $1(1.26 \%)$ \\
\hline Renal failure & $6(7.59 \%)$ \\
\hline Acute kidney injury & $2(2.53 \%)$ \\
\hline Nephrotoxicity & $1(1.26 \%)$ \\
\hline Anemia & $31(39.2 \%)$ \\
\hline Pancytopenia & $1(1.26 \%)$ \\
\hline
\end{tabular}

The assessment of total ADR profile revealed cutaneous adverse drug reactions accounting for maximum ADRs $(44.30 \%)$, hematological toxicities $(40.50 \%)$, renal toxicity $(11.39 \%)$ and gastrointestinal ADRs (3.79\%) (Figure 2).

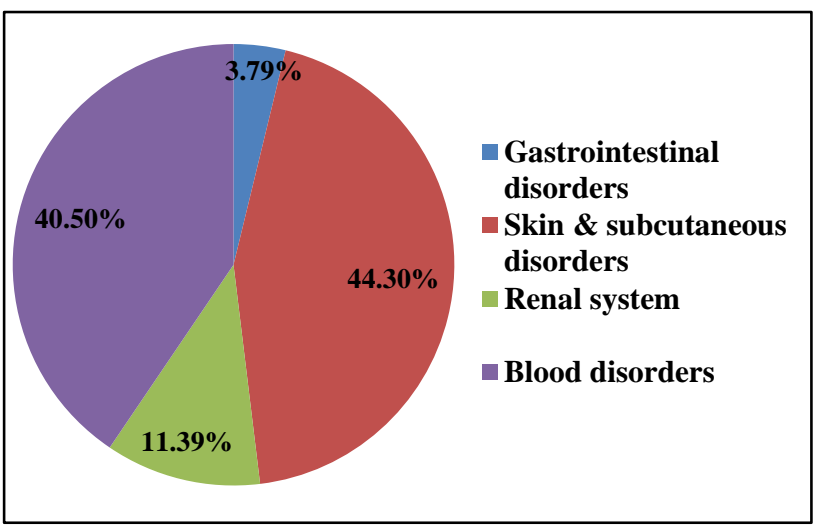

Figure 2: Total no of ADR'S grouped as per system organ classification $(n=79)$.

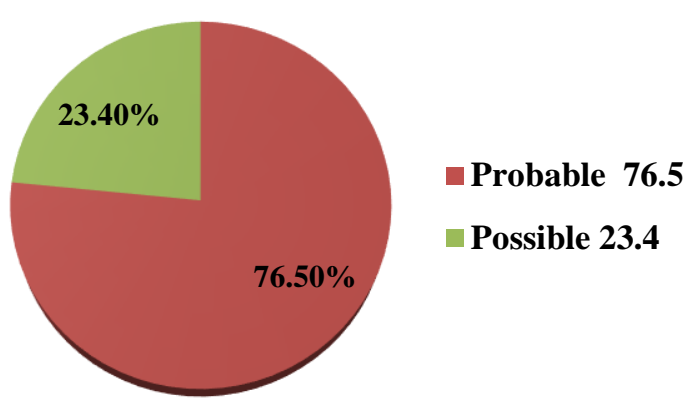

Figure 3: Causality assessment of reported adverse drug reactions (as per WHO-UMC scale and Hartwig Siegel scale respectively).
The reported ADRs were assessed for causality using WHO-UMC causality assessment scale. 36 patients presented with ADRs are probable $(76.5 \%)$ and 11 patients with ADRs are possible (23.4\%) (Figure 3). The severity was assessed using Hartwig and Siegel scale, 93.6\% of cases were found to be mild ADRs while $2.1 \%$ and $4.3 \%$ of cases were found to be moderate and severe ADRs respectively (Figure 4).

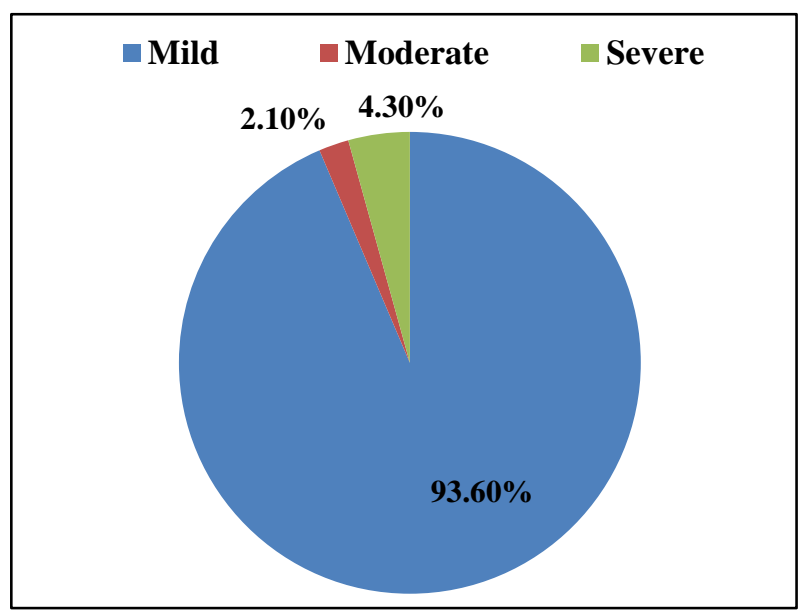

Figure 4: Severity assessment of reported adverse drug reactions (as per WHO-UMC scale and Hartwig Siegel scale respectively).

Among the reported ADRs with TLE regimen in $\mathrm{n}=36$ cases $(76.59 \%)$ efavirenz was stopped and the patients were continued on tenofovir and lamuvidine and later ritonivir/azatanavir were added. In $n=2$ cases $(4.25 \%)$ the doses of the drug were reduced and $n=9(19.14 \%)$ the dose was not changed. The outcome of the reported ADRs with TLE showed $n=19(40.4 \%)$ have recovered and $n=28$ $(59.5 \%)$ were recovering (Figure 5$)$.

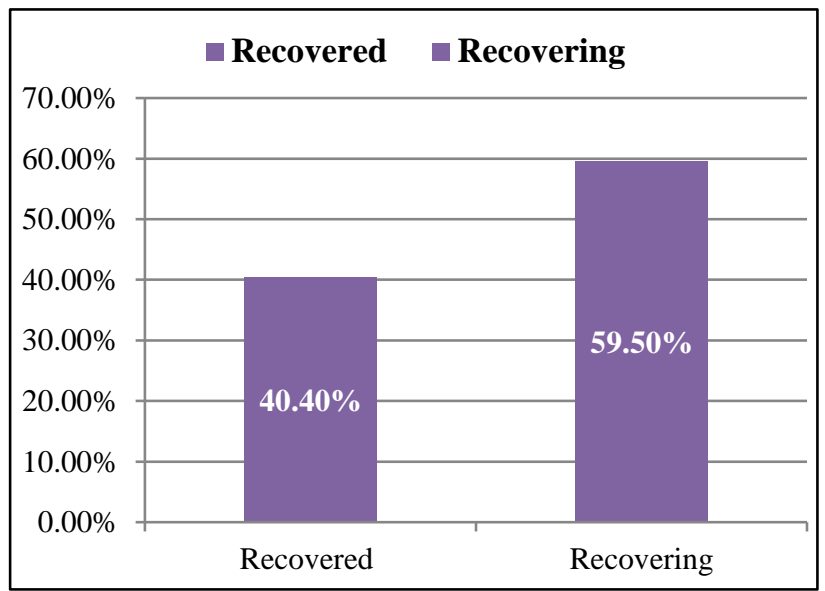

Figure 5: Outcome of patients with TLE regimen.

\section{DISCUSSION}

Occurrence of adverse events are one of the commonest causes for poor adherence to treatment. Hence evaluation 
of AEs may help clinicians to optimize the drug regimens. The present study has reported the incidence, types causality and severity of suspected adverse events with TLE regimen in HIV positive patients in ART centre of tertiary hospital over a period of 6 months.

The present study has shown a frequency of AEs in HIV patients as $17.43 \%$, comparable with the prevalence of $19.73 \%$ reported by Kumari R et al. ${ }^{12}$ This study reported the prevalence of ADRs with ZLE regimen $31.57 \%$ followed by ZLN regimen $20.05 \%$ and TLE regimen showed $19.73 \%$ and TLZR regimen $10.96 \%$. Due to high rates of ARV therapy associated ADRs, the patients are now treated using tenofovir containing regimen as $1^{\text {st }}$ line ARV treatment. Similar results were also reported by Lieketseng et al, tenofovir containing regimen was used as $1^{\text {st }}$ line ARV regimen because other regimen (ZLN /ZLE) have high rate of ADRs. ${ }^{6}$ The same TLE regimen has been found with lower ADR rates in present study.

In present TLE based study, cutaneous ADRs were presented as generalized rash, pruritis, maculopapular rash and erythema which was mild to moderate. NNRTIs such as efavirenz, delaveridine, nevirapine can cause skin rash. The rash associated with NNRTIs is usually erythematous, maculopapular and wide spread. ${ }^{13,14}$ This is also supported by case report of Paik $\mathrm{S}$ et al, tenofovir was also introduced along with efavirenz but there was no previous report or evidence of Steven Johnsons syndrome (SJS) with Tenofovir in the indexed literature. ${ }^{15}$ However, there is an incidence of association of SJS with efavirenz albeit only in less than $0.14 \%$ of cases. ${ }^{15}$

The haematological ADRs were anaemia (mild - moderate) and pancytopenia was reported in 1 patient. Tenofovir based regimen was found to be milder with regard to Haematological ADRs compared to Zidovudine based regimens (ZLN /ZLE). ${ }^{3}$

Present study has also reported renal adverse events as renal failure, acute kidney injury and nephrotoxicity and also gastrointestinal ADRs. The ADRs due to efavirenz were largely nonspecific with some patients showing raised serum transaminase levels suggestive of hepatotoxicity. A case report has also suggested that the risk of hepatotoxicity with efavirenz could be higher if used along with tenofovir. ${ }^{16,17}$ The most commonly reported ADR towards tenofovir is gastrointestinal effects; tenofovir induced nephrotoxicity is explained by mitochondrial DNA depletion which causes mitochondrial toxicity; other reactions seen towards other NRTIs are less common with Tenofovir. ${ }^{18-20}$

Causality assessment of ADRs as per WHO-UMC causality revealed $76.5 \%$ of adverse events as probable and $23.4 \%$ were found to be possible in the study. It is important to perform causality assessment according to WHO causality assessment scale of the suspected drug reaction in order to determine whether drug discontinuation is mandatory as well as to put emphasis on patient education in order to avoid development of adverse events in the future.

Limitations of the study should also be considered. Being a tertiary hospital, which is associated with peripheral area hospitals, the patients who were enrolled for ARV therapy were entrusted to Peripheral ART care centers. So most of the patients may not report to the tertiary center in case of any adverse event reported. Moreover, the study was conducted for short period and is limited to one ART center. Multicentric studies involving large sample size are required to provide more valuable data on incidence and pattern of adverse events in HIV patients and also the presence of other confounding factors which could have affected the final outcome of the study were beyond the scope of current study.

Despite these limitations, present study has certain notable strength. The ADR analysis was based on active surveillance of clinical and laboratory parameters.

\section{CONCLUSION}

The most common AEs reported were the cutaneous ADRs, anemia, renal ADRs and gastro- intestinal disturbances in the study. This study focuses the importance of active ADR monitoring. ADR surveillance is an integral component of monitoring and evaluation in the ART program. The goal of monitoring is to detect the early toxicities and adverse effects to support safe use of ART, thus improving the compliance and treatment outcome.

\section{ACKNOWLEDGEMENTS}

The authors gratefully acknowledge Dr. Ushasree T. S., Professor and Head of the Department, Department of Pharmacology, Gandhi Medical College, Dr. Deepak, Deputy Program Director, Centre of excellence, Gandhi Hospital and ART Centre, Center of Excellence Gandhi Hospital, Adverse Drug Monitoring Centre (AMC) PVPI Department of Pharmacology, Gandhi Medical College, Secunderabad, Telangana, India.

Funding: No funding sources

Conflict of interest: None declared

Ethical approval: The study was approved by the Institutional Ethics Committee

\section{REFERENCES}

1. Rather ZA, Chowta MN, Raju GP, Mubeen F. Evaluation of the adverse reactions of antiretroviral drug regimens in a tertiary care hospital. Indian $\mathbf{J}$ Pharmacol. 2013 Mar;45(2):145.

2. Jha AK, Gadgade A, Shenoy AK, Chowta MN, Ramapuram JT. Evaluation of adverse drug reactions in HIV positive patients in a tertiary care hospital. Perspectives Clin Res. 2015 Jan;6(1):34. 
3. Mukherjee S, Era N, Saha B, Tripathi SK. Adverse drug reaction monitoring in patients on antiretroviral therapy in a tertiary care hospital in Eastern India. Indian J Pharmacol. 2017 May;49(3):223.

4. Kumarasamy N, Vallabhaneni S, Cecelia AJ, Yepthomi T, Balakrishnan P, Saghayam S, et al. Reasons for modification of generic highly active antiretroviral therapeutic regimens among patients in southern India. JAIDS. 2006 Jan 1;41(1):53-8.

5. Severe P, Leger P, Charles M, Noel F, Bonhomme G, Bois $G$, et al. Antiretroviral therapy in a thousand patients with AIDS in Haiti. N Eng J Med. 2005 Dec $1 ; 353(22): 2325-34$.

6. Masenyetse LJ, Manda SO, Mwambi HG. An assessment of adverse drug reactions among HIV positive patients receiving antiretroviral treatment in South Africa. AIDS Res Therapy. 2015 Dec;12(1):6.

7. Luma HN, Choukem SP, Temfack E, Ashuntantang G, Joko HA, Koulla-Shiro S. Adverse drug reactions of Highly Active Antiretroviral Therapy (HAART) in HIV infected patients at the General Hospital, Douala, Cameroon: a cross sectional study. Pan African Med J. 2012;12(1)

8. UNAIDS. Report on the global HIV/AIDS epidemic. Joint united nations Programme on HIV/AIDS. 2008.

9. The National AIDS control organization. National guidelines for implementation of anti-retroviral therapy (ART) draft version. Ministry of health and FW, Govt. of India 2004. Available at: www.nacoonline.org.pdf.

10. The use of WHO -UMC system for standardized case causality assessment. Available at: http://www.whoumc.org/Graphics /24734.pdf.

11. Hartwig SC, Siegel J, Schneider PJ. Preventability and severity assessment in reporting adverse drug reactions. Am J Health-System Pharmacy. 1992 Sep 1;49(9):2229-32.

12. Kumari R, Chandra S, Gari M, Kumari A. An assessment of adverse drug reaction patterns among HIV positive patients receiving antiretroviral therapy in a tertiary care hospital. Int $\mathbf{J}$ Pharmacol Re. 2017;7(4):88-93.

13. Zangerle R. Cutaneous drug reactions in HIV-infected patients. Dermatol Ther. 1999;12:115-30.

14. Hilal-Dandan R, Brunton LL. Antiretroviral agents and treatment of HIV infection. In: Goodman and Gilmans, Manual of Pharmacology and Therapeutics. 2nd ed. New York:Mcgraw Hill Education;2014:9931014.

15. Paik S, Pal A, Sen S, Pramanick N, Tripathi SK. A suspected case of Efavirenz-Induced Stevens-Johnson Syndrome. Drug Safety Case Reports. 2015 Dec 1;2(1):15.

16. Rivero A, Mira JA, Pineda JA. Liver toxicity induced by non-nucleoside reverse transcriptase inhibitors. J Antimicrobial Chemotherapy. 2007 Jan 25;59(3):3426.

17. Lattuada E, Lanzafame M, Carolo G, Gottardi M, Concia E, Vento S. Does tenofovir increase efavirenz hepatotoxicity?. AIDS. 2008 May 11;22(8):995.

18. Perazella MA. Tenofovir-induced kidney disease: an acquired renal tubular mitochondriopathy. Kidney Int. 2010 Dec 1;78(11):1060-3.

19. Fernandez-Fernandez B, Montoya-Ferrer A, Sanz AB, Sanchez-Nino MD, Izquierdo MC, Poveda J, et al. Tenofovir nephrotoxicity: 2011 update. AIDS Res Treatment. 2011;2011.

20. Chowta MN, Kamath P, Ramapuram JT, Shenoy KA, Hadigal S. Evaluation of adverse drug reaction profile of drugs used as first-line antiretroviral therapy. Interdisciplinary perspectives on infectious diseases. 2018;2018.

Cite this article as: Gabbita $\mathrm{P}$, Jillapegu MV, Vangala SLN, Tiruveedhula J. Evaluation of adverse drug reactions of first line antiretroviral drugs in a tertiary care centre of Telangana, India. Int J Basic Clin Pharmacol 2018;7:2091-5. 